\title{
Sorour Khorashadi. « Symbols of the Clan of Qāren and the Rank of Bidaxš in Sasanian Times "
}

\section{Rika Gyselen}

\section{Q OpenEdition}

1 Journals

\section{Édition électronique}

URL : http://journals.openedition.org/abstractairanica/42625

DOI : 10.4000/abstractairanica.42625

ISBN : 1961-960X

ISSN : 1961-960X

Éditeur :

CNRS (UMR 7528 Mondes iraniens et indiens), Éditions de l'IFRI

Référence électronique

Rika Gyselen, «Sorour Khorashadi. « Symbols of the Clan of Qāren and the Rank of Bidaxš in Sasanian Times » », Abstracta Iranica [En ligne], Volume 37-38-39 | 2018, document 6, mis en ligne le 10 mars 2018, consulté le 28 septembre 2020. URL : http://journals.openedition.org/abstractairanica/42625 DOI : https://doi.org/10.4000/abstractairanica.42625

Ce document a été généré automatiquement le 28 septembre 2020

Tous droits réservés 


\title{
Sorour Khorashadi. « Symbols of the Clan of Qāren and the Rank of Bidaxš in Sasanian Times »
}

\author{
Rika Gyselen
}

\section{RÉFÉRENCE}

Sorour Khorashadi. « Symbols of the Clan of Qāren and the Rank of Bidaxš in Sasanian Times ", International Journal of the Society of Iranian Archaeologists, 1, 2, 2015, p.107-117.

1 Malgré un titre attractif, cet article n'apporte rien aux connaissances. Les références bibliographiques ne sont pas à jour (aucune référence bibliographique (non-iranienne) après 1992). De plus, le travail éditorial de cet article laisse beaucoup à désirer : pourquoi ne pas remplacer un terme comme 'relic' par un terme précis comme 'silverware', 'silver plate', etc.; pourquoi garder des transcriptions comme Vuzorgfarmzār alors que des sources épigraphiques moyen-perse attestent clairement le titre wuzurg-framadār ; sans parler des coquilles dans des noms propres, des espaces non respectés, etc.

2 Après une introduction sur le terme bidaxš, S.K. commence son exposé avec un plat d'argent, communément désigné comme le plat de Mtskheta où il fut découvert dans les années 1959. Il existe un large consensus (et il est un peu superflu de le rappeler d'une manière fort alambiquée) pour identifier le buste sur ce plat d'après l'inscription qui y est gravée « Pābag, bidaxš, pus Ardašīr, bidaxš, ... » (l'auteur aurait dû au moins mentionner le début de ce titre). Ce buste porte un kulāf rehaussé d'un symbole composé d'un cercle et d'un croissant, un symbole qu'on retrouve sur un personnage du relief de Wahrām II à Naqsh-i Rustam (personnage à l'extrême droite). On identifie le possesseur du plat aussi avec le Pābag bidaxš qui est mentionné dans l'inscription de Narseh (NPi Skjaervø 1983, 3.1., p. 42, 1. 15/14 ; 3.2, p. 44). 
3 Le deuxième rapprochement entre le personnage du plat avec d'autres représentations est beaucoup plus spéculatif, et reste, du moins à notre avis, du niveau de l'hypothèse à confirmer. Le personnage sur le plat tient entre ses doigts une sorte de bourgeon. Un même type de bourgeon figure sur le kuläf d'un personnage sur le relief de Wahram II à Naqsh-i Wahrām (à l'extrême gauche) et ce même motif est utilisé dans la composition du bandeau autour du kuläf de l'ennemi terrassé par Ohrmazd II sur le relief de Naqsh-i Rustam et pas sur le kulāf comme l'indique l'auteur. Reste à prouver qu'un même type de motif placé à des endroits différents renvoie à la même chose, en occurrence à l'identité du personnage. Le motif du bourgeon entre les doigts est trop général pour pouvoir servir d'identification.

L'exposé est souvent confus en partie parce que l'auteur répète des spéculations, soit de Hinz, soit de Lukonin. Mais existe-t-il un argument pour substituer le terme bidaxš à celui de satrape de la Géorgie (Hinz), ou de considérer le bourgeon comme l'emblème des Kāren (Lukonin) ?

5 La discussion est alambiquée et se fait à l'aide de spéculations émises il y a bien des années par Hinz et Lukonin (à noter que seulement des ouvrages traduits en persan ont été pris en considération) qui ont certes quelque valeur à cause de leurs longues expériences avec ce genre de matériaux, mais qui restent des spéculations. Entretemps sont apparues d'autres évidences concernant les symboles qui figurent sur le kulāf et il est devenu clair qu'il faut distinguer la fonction des symboles d'après l'endroit où ils figurent : au milieu du kulāf ou sur le bandeau qui entoure la base du kuläf.

On aurait préféré une démonstration claire avec les avis des uns et des autres en note et pas en plein texte. En réalité, cet article ne vaut pas un 'abstract' aussi détaillé, mais il découragera peut-être ceux qui voudraient suivre ce type de démonstration.

\section{AUTEURS}

\section{RIKA GYSELEN}

CNRS, Mondes iranien et indien 